\title{
Local adaptation of the clonal plant Ranunculus reptans to flooding along a small-scale gradient
}

\author{
JOHN P. M. LENSSEN, MARK VAN KLEUNEN*†, MARKUS FISCHER ${ }^{*} \dagger$ \\ and HANS DE KROON \\ Department of Ecology, University of Nijmegen, Toernooiveld 1, 6525 ED Nijmegen, the Netherlands, and $\dagger$ Institute \\ of Environmental Sciences, University of Zurich, Wintherthurerstrasse 190, CH-8057 Zurich, Switzerland
}

\begin{abstract}
Summary
1 Plant species are known to segregate along small-scale flooding gradients. We tested whether differences in flooding duration can also result in genetic differentiation in the clonal species Ranunculus reptans, which naturally grows in both a lakeside microhabitat and a landside microhabitat with shorter periods of flooding.

2 We compared traits related to fitness, and clonal life-history traits, of 432 plants representing nine genotypes from each microhabitat, grown without flooding or with short or long flooding duration. We also determined aerenchyma contents and carbohydrate use efficiencies during flooding in plants of these 18 genotypes.

3 In the flooding treatments, genotypes from the lakeside microhabitat produced significantly more rosettes and rooted rosettes than genotypes from the landside microhabitat. This indicates small-scale local adaptation to flooding duration in $R$. reptans.

4 Unexpectedly, genotypes from the landside microhabitat had a higher proportion of aerenchyma in their roots than those from the lakeside microhabitat. Carbohydrate use efficiency was high in all genotypes. These physiological traits cannot therefore explain the observed local adaptation.

5 Genotypes from the lakeside microhabitat produced shorter stolon internodes than genotypes from the landside microhabitat when flooded. Moreover, in the treatment with long flooding duration, there was selection for reduced stolon internode lengths, which might help to reduce respiratory losses. This suggests that local adaptation is a consequence of differences in plasticity of internode length.

6 Our results indicate an important role for flooding in plant microevolution by demonstrating that variation in flooding duration can induce intraspecific specialization even within populations. Physiological traits that determine differences in flooding tolerance between species do not, however, seem to have played a key role in this differentiation.
\end{abstract}

Key-words: aerenchyma, carbohydrate storage, clonal plant, flooding, local adaptation, microevolution, phenotypic plasticity, Ranunculus

\section{Introduction}

Variation in duration of flooding is an important factor maintaining species diversity in plant communities (Keddy 1984; Pollock et al. 1998; Silvertown et al. 1999) because species can be specialized for different flooding regimes and many species can therefore coexist on a larger spatial scale (Keddy 1984; Silvertown et al. 1999,

Correspondence: John P. M. Lenssen (tel. +31 2436533 47; fax +31 2436524 09; e-mail John.Lenssen@sci.kun.nl).

*Present address: Institute of Biochemistry and Biology, University of Potsdam, Villa Liegnitz, Lennéstr. 7a, D-14471 Potsdam, Germany.
2001). Evidence for such a niche separation mechanism is provided by large differences between species in survival and growth responses to flooding duration (Crawford 1992; He et al. 1999; Vervuren et al. 2003), which are associated with differences in physiological and morphological traits. For example, species from habitats with long flooding periods may reduce respiratory losses when flooded by reducing their size (Sand-Jensen \& Frost-Christensen 1999; Voesenek et al. 2004) and may also increase photosynthesis by improving internal aeration (Justin \& Armstrong 1987; He et al. 1999) and increase carbohydrate use efficiency (Crawford 1992).

Niche separation along flooding gradients, and accompanying differences in physiological traits, suggest that 
flooding is an important selection pressure on plants (Silvertown et al. 2001). If so, flooding may also result in intraspecific differentiation, unless phenotypic plasticity in morphological and physiological traits (Sultan \& Bazzaz 1993) or gene flow (Stanton et al. 1997) overrides the impact of selection. A number of studies have indicated that there is genetic variation within species in all of the physiological traits mentioned above, suggesting that there is the potential for selection (Linhart \& Baker 1973; Keeley 1979; Chan \& Burton 1992; Robe \& Griffith 1998; Lynn \& Waldren 2002, 2003). Moreover, genetic differentiation in these traits has been found over a small spatial scale along flooding gradients (e.g. Linhart \& Baker 1973; Lynn \& Waldren 2002), suggesting local adaptation.

Genetic differentiation in physiological and morphological traits can only be attributed to local adaptation if there is also differentiation in fitness responses to flooding, and if the effects of these traits on fitness differ between flooding environments (Linhart \& Grant 1996; Ackerly et al. 2000). In Trifolium repens, seed families with higher ADH (alcohol dehydrogenase) activities during flooding had greater flood tolerance (Chan \& Burton 1992), and seed families from a site without flooding history had lower ADH levels than those from a frequently flooded site. However, we are not aware of any well-replicated study that has tested for local withinpopulation adaptation in response to flooding.

In the present study, we tested whether variation in flooding duration has resulted in genetic differentiation through selection on physiological and morphological traits in the stoloniferous herb Ranunculus reptans. This species grows near freshwater lakes along flooding gradients from low elevation 'lakeside' microhabitats with long flooding periods to higher elevation 'landside' habitats with shorter flooding periods (Prati \& Peintinger 2000). Previous studies have demonstrated a high degree of both molecular and quantitative genetic variation within populations (Fischer et al. 2000a,b), and specialization of genotypes from the landside microhabitat to competitive environments (Prati \& Schmid 2000; van Kleunen \& Fischer 2001), indicating that microevolution of specialists is not likely to be restricted by insufficient genetic variation in this species. To address whether variation in flooding duration may result in local adaptation in $R$. reptans, we asked the following specific questions: (i) Is there variation among genotypes in physiological and morphological traits, and in fitness under different flooding conditions? (ii) If so, does this variation represent genetic differentiation between or within microhabitats? (iii) Does selection on morphological and physiological traits differ between non-flooded environments and environments with short or long flooding durations?

\section{Methods}

\section{STUDY SPECIES}

Ranunculus reptans L. (Ranunculaceae) is a stoloniferous, rosette-forming herb with a circumpolar distribution, which is mainly confined to the temperate to borealsubarctic zones (Hess et al. 1980). In central Europe, the species only grows on periodically inundated lakeshores with low vegetation cover, and today is concentrated around Lake Constance on the borders of Austria, Germany and Switzerland (latitude $47^{\circ} 40^{\prime} \mathrm{N}$, longitude $9^{\circ} 20^{\prime} \mathrm{E}$ ). Within populations, there is a consistent gradient between the two microhabitats. Plants in the lakeside microhabitat, close to the winter water level of the lake, experience an average summer-inundation period of 150 days and little competition from other species. Landside plants are about $30 \mathrm{~cm}$ higher in elevation and experience an average inundation period of 80 days and competition from grasses (Prati \& Peintinger 2000).

Rosettes of $R$. reptans may have up to 20 leaves with leaf blades $10-50 \mathrm{~mm}$ long and $1-5 \mathrm{~mm}$ wide. When flooded, short, filiform leaves replace terrestrial leaves. Rosettes form stolon branches from meristems in the axils of leaves. Stolons consist of rooted and unrooted rosettes connected by stolon internodes (Prati \& Peintinger 2000). In terrestrial conditions, each roset te may produce one flower, and flowering does not prevent rooting or production of new rosettes (Prati \& Schmid 2000).

\section{PLANT MATERIAL}

To sample plant material comprehensively, we collected equal numbers of plants from the landside and lakeside microhabitat in each of nine populations around Lake Constance in 1995 and 1997 (totalling 82 plants, for further details see van Kleunen \& Fischer 2001). Because earlier work has shown that genetic differentiation between microhabitats is consistent among populations (Prati $\&$ Schmid 2000), we selected nine plants from the landside microhabitat and nine plants from the lakeside microhabitat independent of population of origin for this study. Random amplified polymorphic DNA (RAPD) analysis confirmed that all sampled plants were genetically different, i.e. that they belonged to different genets (Fischer et al. 2000a).

To reduce the possibility of maternal carry-over effects, we vegetatively propagated the 18 genotypes on a $3: 1$ mixture of sand and compost under uniform conditions and used the third vegetative generation in our experiments. Both pre-cultivation and experiments were carried out in a controlled glasshouse at $c .20^{\circ} \mathrm{C}$ with additional lighting to extend the light period to $16 \mathrm{~h}$.

\section{EXPERIMENT 1: FITNESS AND} MORPHOLOGICAL RESPONSES TO FLOODING

\section{Experimental set-up}

We tested for genetic differentiation in morphological traits and traits related to fitness between landside and lakeside genotypes under flooding conditions similar to those in the natural microhabitats. We grew plants under non-flooded conditions, and under 7 and 14 weeks 


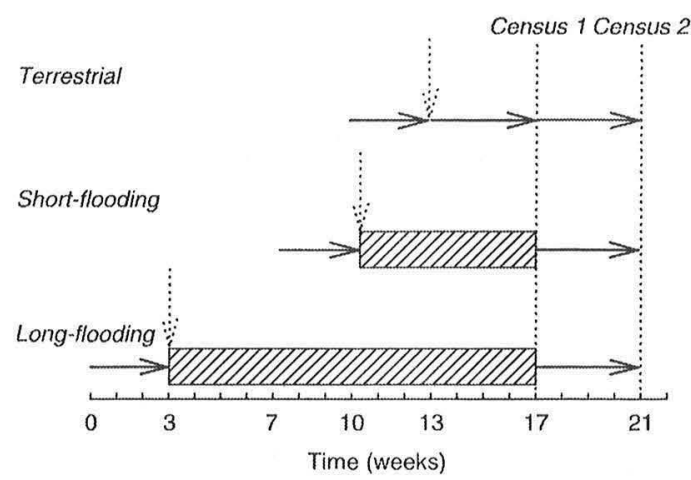

Fig. 1 Time course of treatments in the flooding duration experiment. Horizontal arrows indicate non-flooded periods and hatched bars indicate periods of submergence (flooding). In each environment, the left most horizontal arrow indicates the 3-week acclimation period. The right most horizontal arrow indicates the emersion period, i.e. transition from submerged to non-flooded conditions in case of both flooding treatments. Initial measurements were taken at the times indicated by dotted, vertical arrows. Non-destructive measurements were taken at census 1 (indicated by the left dotted vertical line) and both non-destructive and destructive measurements were carried out at census 2 (indicated by the right dotted vertical line).

of submergence (hereafter referred to as flooding) (Fig. 1). The duration of the non-flooded treatment corresponds to the maximum period of emersion that may be encountered during the growing season in the landside habitat, and short and long flooding treatments approximate submergence periods in the landside and lakeside microhabitats, respectively. The three experimental treatments have different durations, but this does not affect testing of our main hypothesis on genetic differentiation between landside and lakeside genotypes. Based on observations by Prati \& Peintinger (2000), we expected that growth would be strongly reduced during flooding and that treatment effects would mainly emerge during recovery, the 4-week final period in all treatments, i.e. between censuses 1 and 2 (Fig. 1). We started treatments at different times so that final harvests took place at the same time.

We arranged treatments in a randomized block design with four blocks, each with two replicates of genotype $\times$ treatment combination. We filled 72 trays (length $x$ width $\times$ depth $=46 \times 28.5 \times 8 \mathrm{~cm}$ ) with a $3: 1$ mixture of sand and compost and covered it with fine gravel. We allocated 24 trays to each treatment and randomly assigned rosettes to six positions in each tray so that two rosettes of each of the 18 genotypes were included in the six trays of each block and all rosettes planted in the same tray belonged to different genotypes (a total of 432 plants). After an acclimation period of 3 weeks (Fig. 1), trays assigned to the two flooding treatments were submerged in one of four circular basins (diameter $x$ depth $=180 \times 90 \mathrm{~cm}$, one per block) filled with nonchlorinated tap water. To prevent growth of algae in the water, we added Daphnia sp. to the basins and used a filtering system. Weekly measurements in all basins with a YSI integrated oxygen/YSI temperature device, model 54 with a Pt/Au electrode (Yellow Springs, Ohio, USA) showed that water temperature remained within the range $18-22{ }^{\circ} \mathrm{C}$, which is similar to the water temperatures of Lake Constance during the growing season (Lang 1967), and the oxygen concentration was $9.37 \pm 0.41 \mathrm{mg} \mathrm{L}^{-1}$ (means $\pm \mathrm{SE}$, pooled across censuses and basins). Measurements of photosynthetically active radiation with a cosine-corrected underwater quantum sensor (model LI-192SB connected to a quantum-photometer model LI-185SB; LI-COR, Lincoln, Nebraska, USA) at the water surface and at plant height $5 \mathrm{~cm}$ above the bottom of the basin showed that $38.5 \pm 0.5 \%$ (means $\pm \mathrm{SE}$ ) of the incident light was transmitted through the water layer.

Half the trays in each basin were removed after 7 weeks and the remainder after 14 weeks and positioned in the glasshouse with the non-flooded trays from the same block. Within each block, we randomly assigned trays to new positions every 2 weeks during the recovery period. Plants were regularly watered in the non-flooded treatment and during the acclimation and recovery periods.

\section{Measurements}

To obtain non-destructive estimates of plant size, we determined relationships between morphological traits and dry weight on two separate batches of plants grown under non-flooded and flooded conditions. Initial dry weight (mg) of plants at the start of the experiment was best predicted as

$0.07 \times$ (number of leaves $\times$ length of longest leaf $(\mathrm{mm}))+0.14 \times$ stolon length $(\mathrm{mm}) ; R^{2}=0.64, n=30$

eqn 1

Dry weight of individual rosettes produced under non-flooded conditions was best predicted as

$0.06 \times($ number of leaves $\times$ length of longest leaf);

$R^{2}=0.71, n=133$

eqn 2

and dry weight of individual rosettes produced under flooding as

$0.8+0.017 \times$ (number of leaves $\times$ length of longest leaf); $R^{2}=0.82, n=102$

After the 3-week acclimation period (Fig. 1), we counted the number of leaves of each plant and measured the length of the longest leaf and stolon length and then estimated initial plant dry weight with equation 1 . At the first census, we counted the number of rosettes and of rooted rosettes for each clone as measures of vegetative reproduction (van Kleunen et al. 2000; van Kleunen \& Fischer 2001) and marked them with a toothpick to distinguish them from rosettes formed during the recovery period (between censuses 1 and 2). At the second census we repeated counts of rosette numbers and the initial measurements of morphology and, as a measure of 
sexual reproduction, counted the number of flowers per clone. The morphological measurements were made on each of the first three rosettes produced after the 3-week acclimation period (see Fig. 1) and individual dry weights were estimated from equations 2 and 3 at the end of the experiment. We also measured lengths of the first three stolon internodes formed after the acclimation period before harvesting, drying at $70^{\circ} \mathrm{C}$ for at least $48 \mathrm{~h}$ and weighing. We calculated specific stolon length as the ratio between total length and dry weight of these internodes.

\section{Statistical analyses}

We tested effects of block, tray, genotype, microhabitat of origin (land- and lakeside) and treatment (i.e. nonflooded, short and long flooding duration) on fitness measures and morphological traits with ANOVA, using the statistical package SPSS version 10.0 (Norusis 1999). We considered microhabitat of origin and treatment as fixed factors, and tray, block and genotype as random factors. Tray was nested within block and treatment, and genotype was nested within microhabitat of origin. For analysis of number of rosettes and rooted rosettes, counts at census 1 and 2 were analysed with repeated measures analysis of variance. Initial clone size was used as a covariate in analyses of all fitness measures. Significant flooding treatment effects and interactions were decomposed into two orthogonal contrasts to test the response to flooding per se (contrasting nonflooded vs. both flooding treatments) and the response to flooding duration (contrasting short vs. long flooding durations). For the number of rosettes, we also did separate ANOVAS for each treatment.

\section{EXPERIMENT 2: AERENCHYMA CONTENT IN RESPONSE TO FLOODING}

\section{Experimental set-up and measurements}

We determined the amount of aerenchyma in each of the 18 genotypes in response to flooding because this is the main trait determining internal transport of oxygen and carbon dioxide in flooded plants (Justin \& Armstrong 1987; Rijnders et al. 2000).

Pre-cultivation and glasshouse conditions were similar to those in experiment 1 . We planted vegetatively propagated rosettes of each genotype into individual 800-mL black polythene pots filled with pure river sand covered with a thin layer of fine gravel. After 3 weeks of acclimation, we assigned one replicate of each genotype to non-flooded conditions and one to flooded conditions by placing it in one of the basins used in experiment 1 . The procedure was repeated eight times starting at 2day intervals and using a different basin to the previous one. Each replicate series was considered as a separate block in the analysis.

Two weeks after starting the treatments we harvested the plants and dissected them into roots, stolons and petioles (excluding leaf laminae), which were carefully blotted with paper tissues to remove adhering water. We determined porosities of the three plant parts by using the pycnometer method (Jensen et al. 1969) with the exception that air was removed by evacuation. This method determines the ratio between volume of air in the tissue and total tissue volume. The ratio generally correlates strongly with the amount of aerenchyma as assessed by cross-sections if tissue fresh weight is over $100 \mathrm{mg}$ (Visser \& Bögemann 2003). We only included samples larger than $100 \mathrm{mg}$ in our final analysis.

\section{Statistical analyses}

Data on aerenchyma content of roots, stolons and petioles were unbalanced because small samples had to be excluded. Therefore, we used restricted maximumlikelihood (REML) analysis of variance (Payne et al. 1993). We considered microhabitat of origin (land- vs. lakeside) and flooding treatment (non-flooded vs. flooded) as fixed effects, and tested them with the Wald statistic, which follows an asymptotic chi-squared distribution. We considered block and genotype as random effects, and tested them with a likelihood ratio test.

\section{EXPERIMENT 3: STORAGE AND USE OF CARBOHYDRATES IN FLOODED PLANTS}

The ability to increase carbohydrates, or at least maintain a neutral carbon balance through photosynthesis, under water is best reflected by the change in soluble and stored carbohydrates because these are the first carbon sources to be depleted when demand exceeds assimilatory supply (Setter et al. 1997). We therefore determined the change in carbohydrate levels in each of the 18 genotypes during 2 weeks of flooding under daylight conditions. We also measured carbohydrate use during 2 weeks of flooding in continuous darkness to determine the ability of each genotype to mobilize and respire stored carbohydrates in the absence of photosynthetically generated oxygen. This is a typical characteristic of flood-tolerant species (Laan \& Blom 1990; Crawford 1992) that may be necessary during nights or in turbid conditions (Rijnders et al. 2000).

Carbohydrate measurements were restricted to the roots because these parts are the most likely plant parts to experience oxygen deficiency, due to their distance from the oxygen-generating shoots and their fast rates of respiration (Vartapetian \& Jackson 1997). Preliminary analyses showed that roots contained a large fraction of the total non-structural carbohydrate pool $(42 \pm 4 \%)$ and the largest fraction of the total plant starch pool $(64 \pm 5 \%$, both means \pm SE, $n=24)$.

\section{Experimental set-up and measurements}

We propagated rosettes as in experiment 2 with six replicate series (blocks), each with three replicates per genotype. One replicate per genotype was sampled 
immediately before the start of flooding, one after 2 weeks of flooding under continuously dark conditions, and one after 2 weeks of flooding under daylight. Dark and daylight conditions were imposed by placing the plants in containers covered with black and transparent plastic foil, respectively. The water temperature in containers did not differ between the two light treatments.

We harvested all plants between 13.00 and 15.30 to minimize variation in carbohydrate levels due to daily fluctuations. Plants were quickly washed free of soil, roots were cut off and put into liquid nitrogen and stored in a freezer at $-80^{\circ} \mathrm{C}$ until further processing. After freezedrying, we used c. $10 \mathrm{mg}$ of fine cut material to measure non-structural carbohydrates. We extracted all soluble sugars (hexose units) in $4 \mathrm{~mL} 80 \%$ ethanol during $30 \mathrm{~min}$ in a shaking water bath at $80^{\circ} \mathrm{C}$. After centrifugation, we repeated extraction of the residue in $2 \mathrm{~mL} 80 \%$ ethanol. We assayed the starch fraction by boiling the residue in $3.5 \mathrm{~mL}$ of demineralized water for $3 \mathrm{~h}$ and then incubating the solution for $24 \mathrm{~h}$ at $37^{\circ} \mathrm{C}$ with $1 \mathrm{~mL}$ solution containing $13 \mathrm{mg}$ amyloglucosidase (75 units $\mathrm{mg}^{-1}$ : EC 3.2.1.3, Sigma, St. Louis, USA) in $100 \mathrm{~mL} \mathrm{Na}^{+}$ acetate buffer at $\mathrm{pH} 4.5$. We measured both the soluble carbohydrates in the ethanol extraction and the glucose released from hydrolysis of starch with a Shimadzu UV1205 spectrophotometer (Shimadzu Corporation, Maryland, Columbia, USA) using anthrone as a colour reagent (Yemm \& Willis 1954). Internal standards were included in each series.

\section{Statistical analysis}

Carbohydrate contents were ln-transformed to achieve homogeneity of variances and normal distribution of residuals (Sokal \& Rohlf 1995), and analysed with ANOVA according to a randomized block design. We considered treatment (non-flooding, flooding under daylight, flooding under dark conditions) and microhabitat of origin (land- vs. lakeside) as fixed factors, and block and genotype as random factors. Genotype was nested within microhabitat of origin. Significant treatment effects were decomposed into two orthogonal contrasts to analyse the change in concentration of carbohydrates during flooding (contrasting initial values of non-flooded plants vs. values of plants after flooding, independent of light conditions) and the response to light conditions during flooding (contrasting values of plants after flooding under daylight conditions vs. values of plants after flooding under continuous darkness). Because tests on total non-structural carbohydrate content and starch content gave similar results we only report results for starch.

\section{SELECTION GRADIENT ANALYSIS}

To test whether there is selection on the measured morphological and physiological traits in non-flooded and flooded environments, we used selection gradient analyses (Lande \& Arnold 1983). We regressed geno- typic values of fitness, measured as the number of rooted rosettes at the end of the experiment (census 2), on genotypic values of the morphological and physiological traits for each of the three treatments of experiment 1 separately. Results were similar whether we used the number of rooted rosettes at census 1 as measure of fitness, or the total number of rosettes at each census. We used genotypic instead of individual va lues to avoid environmentally induced covariation (Rausher 1992). Therefore, we only analysed traits for which ANOVA revealed significant genetic variation. To allow comparison between treatments and traits we used relative fitness (calculated per treatment) as the dependent variable and express regression coefficients in units of standard deviations (Lande \& Arnold 1983).

\section{Results}

\section{FITNESS RESPONSES TO FLOODING}

All plants continued to produce rosettes during flooding and the longest flooding treatment produced the largest number of rosettes (Fig. 2a,b, Table 1). However, flooding had a negative effect on plant performance as indicated by the fact that plants in the treatment with short flooding duration produced fewer rosettes than non-flooded plants even though the latter had 3 weeks less time to grow (Fig. 2a,b). Moreover, the number of flowers per plant at the end of the experiment (census 2) was highest in the non-flooded treatment (mean $\pm \mathrm{SE}=4.8 \pm 0.3$ ), lowest for plants in the treatment with short flooding duration $(0.8 \pm 0.1)$ and intermediate for plants in the treatment with long flooding duration $(1.6 \pm 0.2)$.

In both flooding treatments, but not in the non-flooded treatment, genotypes from the lakeside microhabitat produced more rosettes and rooted rosettes than genotypes from the landside microhabitat (Fig. 2a,b; non-flooded treatment, $F_{1,16}=0.23, P=0.394$; short flooding treatment, $F_{1,16}=5.44, P=0.033$; long flooding treatment, $F_{1,16}=9.44, P=0.007 ; F$-values for rooted rosettes only).

In addition to genetic differentiation between microhabitats of origin, there was significant variation between genotypes within microhabitats of origin in the number of rosettes, rooted rosettes and flowers produced in response to flooding treatments (significant genotypeflooding treatment interactions in Table 1). This interaction was mainly caused by differences in genotypic responses to flooding per se rather than to flooding duration (Table 1).

ROSETTE SIZE AND STOLON INTERNODE LENGTH IN RESPONSE TO FLOODING

Rosettes were significantly smaller when produced under flooded conditions than under non-flooded conditions (Fig. 2c,d, Table 1). The extent to which rosette size was decreased by flooding varied significantly between genotypes, but this was not related to their microhabitats of origin (Table 1). 

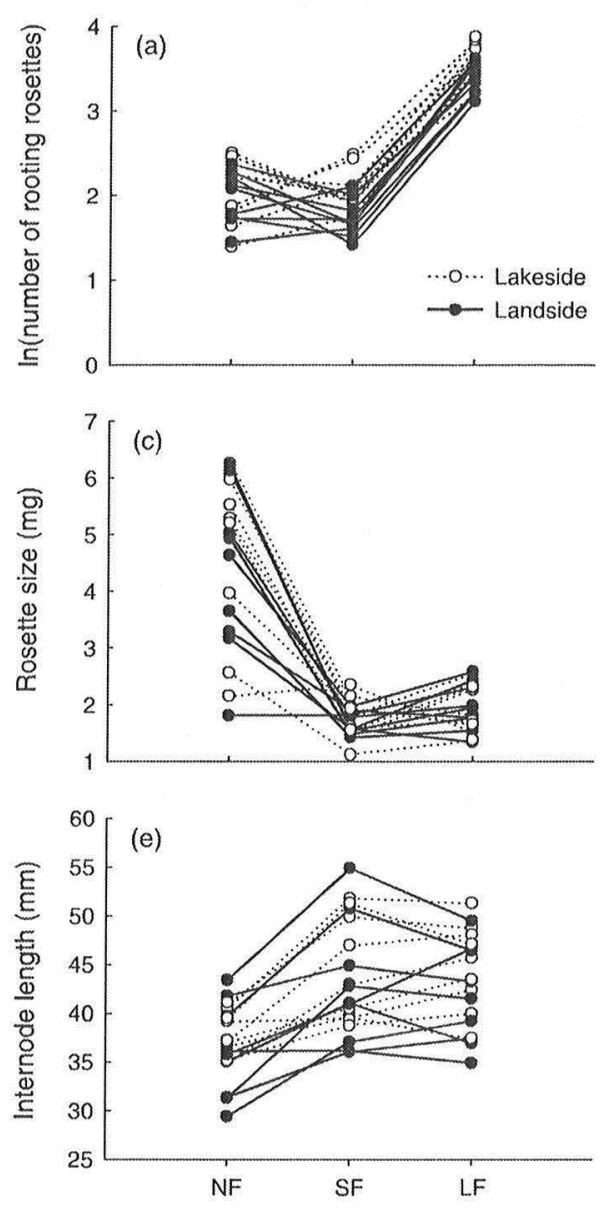
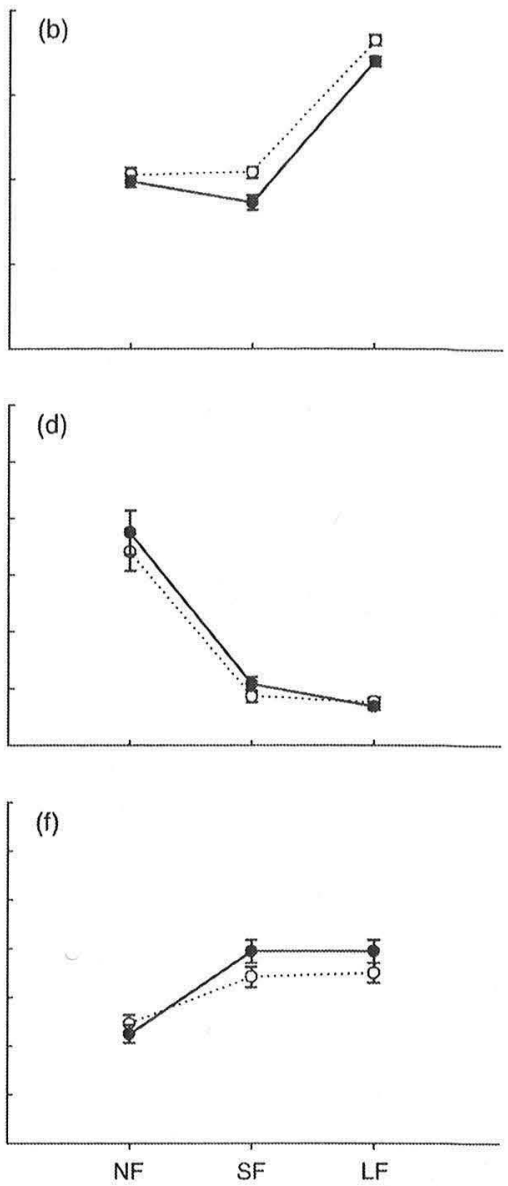

Fig. 2 Number of rooted rosettes at the second census (a and b), rosette size (c and d) and stolon internode length (e and f) of Ranunculus reptans in the non-flooded treatment (NF) and after a short (SF) and long flooding (LF) duration. Rooted rosettes were counted at the second census but measurements of rosette size and stolon internode length were taken at the first census and therefore refer to plant structures formed during flooding in case of SF and LF treatments. Left panels (a, c and e) show separate genotype means and right panels ( $b, d$ and $f$ ) show means $\pm S E$ for lakeside (open symbols) and landside (closed symbols) microhabitats.

Plants produced significantly longer stolon internodes in response to flooding regardless of flooding duration (Fig. 2e,f, Table 1). The increase of stolon internode length was significantly larger for landside than lakeside genotypes (Fig. 2e,f, Table 1). Specific stolon length, on the other hand, increased both in response to flooding per se and in response to flooding duration. The magnitude of this response was similar for all genotypes (Table 1). This indicates that differences in plasticity of stolon internode length between genotypes from the landside and lakeside microhabitats were a consequence of different investments of biomass into stolons.

Both size of individual rosettes and stolon internode lengths of the parts produced between censuses 1 and 2 were significantly smaller when plants had previously been flooded ( $36.7 \%$ reduction, $F_{2.24}=22.4, P<0.001$ and $21.2 \%$ reduction, $F_{2.24}=116.43, P<0.001$ for rosette size and stolon internode length, respectively).

\section{AERENCHYMA CONTENT}

In stolons, flooding increased aerenchyma content from $30.3 \pm 1.5 \%$ to $37.8 \pm 1.8 \%$ (Wald statistic $=16.5$,
$P<0.001)$. The aerenchyma content of petioles did not differ significantly between the flooding treatments (non-flooded conditions, $34.9 \pm 1.1 \%$; flooded conditions, $35.0 \pm 2,1 \%$; Wald statistic $=0.0, P=1.00$ ). Flooding significantly increased aerenchyma content of roots (Wald statistic $=6.1, P=0.014$, Fig. 3 ).

Contrary to our expectations, root aerenchyma content was significantly higher for genotypes from the landside microhabitat than for genotypes from the lakeside microhabitat (Wald statistic $=4.7, P=0.030$ ) in both treatments (Fig. 3), suggesting that selective forces other than flooding are responsible for differences in aerenchyma content.

STORAGE AND USE OF CARBOHYDRATE IN ROOTS OF FLOODED PLANTS

Starch content (Fig. 4) differed significantly between genotypes $\left(F_{16.251}=2.36, P=0.005\right)$, but did not differ between microhabitats of origin. Treatments significantly affected starch content $\left(F_{2.32}=10.61, P<0.001\right)$, and contrasts indicated that this difference was due to a decline of starch content during flooding (contrast of 
Table $1 F$-values and their significance for variation in rosette number (rooted, total and flowering), rosette size, stolon internode length and specific stolon length. Number of rooted and total rosettes included both census 1 and 2 and were therefore analysed as a within-clone repeated factor. Significant effects of flooding treatment were also decomposed into two orthogonal contrasts to test the non-flooded treatment against both flooding treatments (flooding per se) and to test the treatment with short flooding duration against the one with long flooding duration (flooding duration). Analyses of stolon and rosette size did not include initial clone size, and refer to structures formed during submergence (in case of short and long flooding)

\begin{tabular}{|c|c|c|c|c|c|c|c|}
\hline Source of variation & d.f. & $\begin{array}{l}\text { Number of } \\
\text { rooted rosettes }\end{array}$ & $\begin{array}{l}\text { Total number } \\
\text { of rosettes }\end{array}$ & $\begin{array}{l}\text { Number of } \\
\text { flowers }\end{array}$ & $\begin{array}{l}\text { Rosette dry weight } \\
\text { at census } 1\end{array}$ & $\begin{array}{l}\text { Stolon internode } \\
\text { length }\end{array}$ & $\begin{array}{l}\text { Specific stolon } \\
\text { length }\end{array}$ \\
\hline Initial clone size & 1 & $4.24 *$ & $29.88 * * *$ & $36.61^{* * *}$ & - & - & - \\
\hline Block & 3 & $14.38 * * *$ & $25.06 * * *$ & $10.51 * * *$ & $21.14 * * *$ & $4.98 * *$ & 1.83 \\
\hline Flooding treatment & 2 & $523.11 * * *$ & $459.45^{* * *}$ & $77.44 * * *$ & $193.02 * * *$ & $24.27 * * *$ & $240.66 * * *$ \\
\hline Flooding per se & 1 & $398.10 * * *$ & $160.95 * * *$ & $145.97 * * *$ & $311.61 * * *$ & $48.48^{* * *}$ & $447.20 * * *$ \\
\hline Flooding duration & 1 & $648.12^{* * *}$ & $757.96^{* * *}$ & 2.96 & 2.81 & 0.05 & $34.11 * * *$ \\
\hline Tray $(B \times F)$ & 24 & 1.11 & 1.00 & 1.78 & 0.71 & 1.53 & $1.66^{*}$ \\
\hline Microhabitat & 1 & $7.02 *$ & $5.24 *$ & 0.26 & 0.33 & 0.13 & 0.03 \\
\hline Genotype (M) & 16 & $2.26^{* * *}$ & $3.08 * * *$ & $5.35 * * *$ & $2.29 * * *$ & $7.66 * * *$ & $3.83^{* * *}$ \\
\hline $\mathrm{M} \times \mathrm{F}$ & 2 & 1.21 & 1.75 & 0.12 & 0.57 & $4.87^{*}$ & 2.46 \\
\hline Flooding per se & 1 & - & - & - & - & $8.00 * *$ & - \\
\hline Flooding duration & 1 & - & - & - & - & 0.14 & - \\
\hline $\mathrm{G}(\mathrm{M}) \times \mathrm{F}$ & 32 & $1.71 * *$ & $1.71 * *$ & $2.78 * * *$ & $1.53 *$ & 0.77 & 1.06 \\
\hline Flooding per se & 16 & $2.21 * *$ & $2.42 * *$ & $4.17 * * *$ & $2.32 * *$ & - & - \\
\hline Flooding duration & 16 & 1.17 & 1.00 & 1.47 & 0.74 & - & - \\
\hline Residual: MS (d.f.) & & $0.52(349)$ & $0.38(349)$ & $0.23(349)$ & $0.22(324)$ & $0.03(317)$ & $0.08(290)$ \\
\hline Census & 1 & $741.72 * * *$ & $2584.73 * * *$ & & & & \\
\hline $\mathrm{C} \times \mathrm{B}$ & 3 & 0.58 & $10.92 * * *$ & & & & \\
\hline $\mathrm{C} \times \mathrm{F}$ & 2 & $266.23 * * *$ & $216.09 * * *$ & & & & \\
\hline $\mathrm{C} \times \mathrm{F}$ & 2 & $266.23 * * *$ & $216.09 * * *$ & & & & \\
\hline Flooding per se & 1 & $538.00 * * *$ & $436.60 * * *$ & & & & \\
\hline Flooding duration & 1 & $37.67 * * *$ & $35.60 * * *$ & & & & \\
\hline $\mathrm{C} \times \mathrm{M}$ & 1 & 2.04 & 1.57 & & & & \\
\hline $\mathrm{C} \times \mathrm{G}(\mathrm{M})$ & 16 & $1.80^{*}$ & 1.64 & & & & \\
\hline $\mathrm{C} \times \mathrm{M} \times \mathrm{F}$ & 2 & 0.25 & 0.33 & & & & \\
\hline $\mathrm{C} \times \mathrm{G}(\mathrm{M}) \times \mathrm{F}$ & 32 & $2.02^{* *}$ & $1.67^{*}$ & & & & \\
\hline Flooding per se & 16 & $3.20 * * *$ & $3.00 * * *$ & & & & \\
\hline Flooding duration & 16 & 0.60 & 0.67 & & & & \\
\hline Residual: MS (d.f.) & & $0.05(349)$ & $0.03(349)$ & & & & \\
\hline
\end{tabular}

${ }^{*} P<0.05,{ }^{* *} P<0.01, * * * P<0.001$, d.f. $=$ degrees of freedom.

initial values vs. values of both flooding treatments; $F_{1.32}=$ $20.67, P<0.001)$ and not to a difference between plants flooded under daylight and continuous dark $\left(F_{1,32}=\right.$ $0.47, P=0.63)$. Variation between genotypes in their response to treatments was only marginally significant $\left(F_{32.251}=1.41, P=0.08\right)$.

\section{SELECTION ON PHYSIOLOGICAL. AND} MORPIIOLOGICAL TRAITS

Univariate regressions indicated a marginally significant and significant negative effect of rosette size and stolon internode length, respectively, on fitness measured in

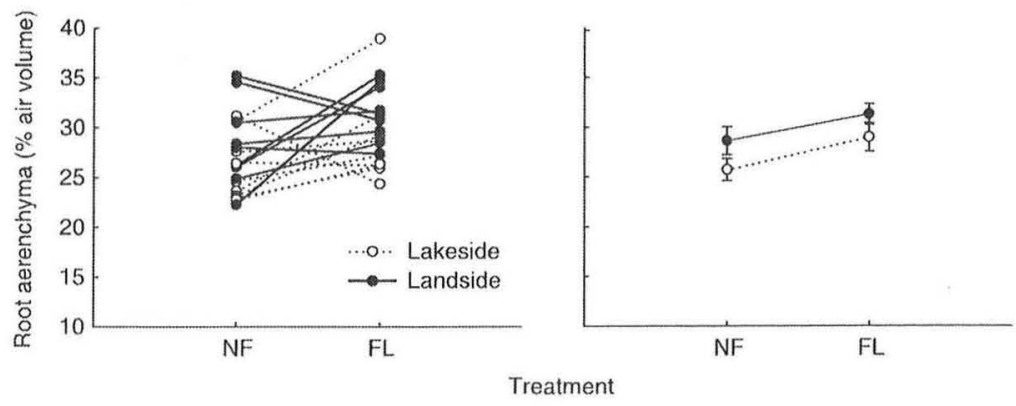

Fig. 3 Root aerenchyma content of genotypes from landside (closed symbols, solid line) and lakeside (open symbols, dashed line) habitats in a non-flooded (NF) and flooding (FL) treatment. Left panel shows separate genotype means and right panel shows means \pm SE for each microhabitat. 

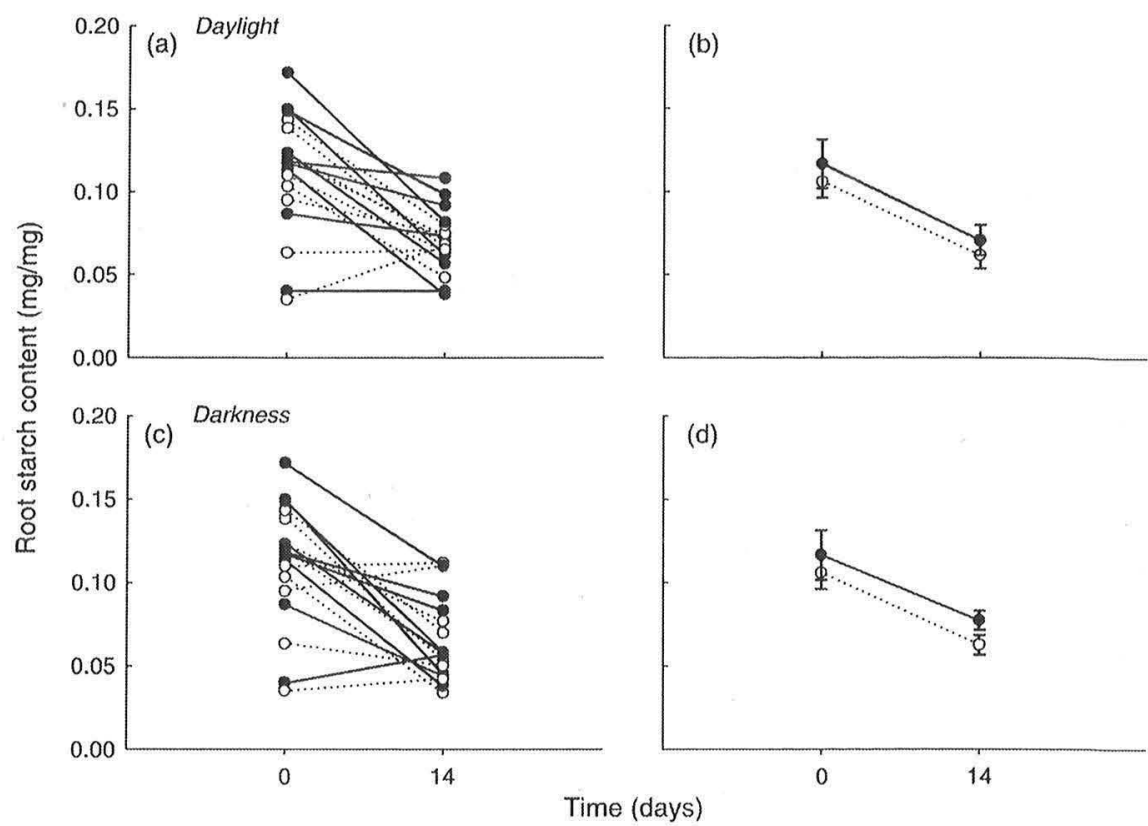

Fig. 4 Change in root starch content during 2 weeks of submergence in daylight ( $a$ and $b$ ) and continuous darkness ( $c$ and d). Left panels ( $a$ and $c$ ) show separate genotype means and right panels ( $b$ and d) show means \pm SE for lakeside (open symbols) and landside (closed symbols) microhabitats.
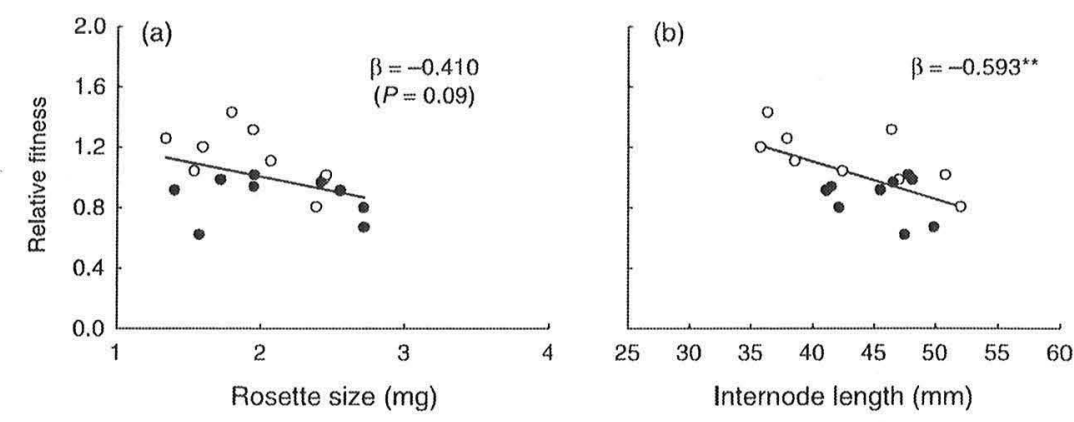

Fig. 5 The relationship between relative fitness, measured as the number of rooted rosettes at census 2, and rosette size (a) and stolon internode length (b) in the treatment with long flooding duration. Symbols indicate genotypic means of lakeside (open symbols) and landside (closed symbols) microhabitats of origin of Ranunculus reptans. Standardized regression coefficients ( $(\beta)$ are indicated in each panel $(* * P<0.01)$.

terms of number of rooted rosettes in the treatment with long flooding duration (Fig. 5). Selection gradients for these traits were not significant in the non-flooded treatment and in the treatment with short flooding duration (all $P>0.10$ ).

\section{Discussion}

LOCAL ADAPTATION TO FLOODING: FITNESS

Plants of $R$ reptans from the lakeside microhabitat, which naturally experience long flooding periods, produced more rosettes and rooted rosettes when grown under flooded conditions than plants from the landside microhabitat (Fig. 2), indicating local adaptation.

In addition to genetic differentiation between microhabitats of origin for fitness traits, we also found significant variation between genotypes within microhabitats of origin. Because the plants originated from nine different populations within each microhabitat, this variation could be thought to reflect differentiation between rather than within populations. However, previous studies on $R$. reptans have shown that variation in fitness-related traits between populations is generally small relative to variation between genotypes within populations and their microhabitats (Fischer et al. 2000a,b; Prati \& Schmid 2000; van Kleunen et al. 2000). Genetic variation within microhabitats may be maintained by temporal or spatial variation in environmental conditions (Sultan \& Bazzaz 1993). The seasonal alternations between flooded and terrestrial conditions that are characteristic for both microhabitats may be responsible for maintaining within-microhabitat genetic variation in flooding responses.

Reports of genetic differentiation along gradients with temporal variation in environmental conditions are 
rare, possibly because such selection pressures can be overridden by gene flow (Stanton et al. 1997). Gene flow is likely to be limited along the flooding gradient within populations of $R$. reptans. Seed dispersal by transport with the rising water level must occur from lakeside microhabitat to landside habitat. However, in most years the terrestrial period is too short for seed production at the lakeside microhabitat. Moreover, pollen flow between both microhabitats is likely to be low because plants in the landside microhabitat may reach the flowering stage when plants in the lakeside microhabitat are still flooded.

The few other studies that have indicated withinpopulation differentiation along flooding gradients (Linhart 1988; Prati \& Schmid 2000; van Kleunen \& Fischer 2001) did so in response to interspecific competition, which is only indirectly determined by flooding duration. To our knowledge this is the first study indicating that flooding itself induces genetic differentiation on a small spatial scale.

LOCAL ADAPTATION TO FLOODING: PHYSIOLOGICAL, TRAITS

Genetic specialization in response to duration of flooding as shown here at the intraspecific level resembles the close relationship between flooding tolerance and position along natural flooding gradients that has frequently been demonstrated in interspecific comparisons (Crawford 1992; He et al. 1999; Vervuren et al. 2003). Flooding tolerance is generally associated with a high aerenchyma content (Justin \& Armstrong 1987; He et al. 1999), a large amount of stored carbohydrates and efficient carbohydrate metabolism (Crawford 1992).

When compared with other species, all genotypes of $R$. reptans appear physiologically well equipped for flooding. Aerenchyma content of roots, stolons and petioles was always higher than $20 \%$, which is in the upper range of values reported for other wetland species (Justin \& Armstrong 1987; He et al. 1999). Further, the decline in root starch content of plants flooded under continuous dark (Fig. 4) suggests that genotypes of $R$. reptans, like many other species from habitats with long flooding periods (Laan \& Blom 1990; Crawford 1992; Lynn \& Waldren 2003), had the capacity to metabolize stored carbohydrates without photosynthetically generated oxygen.

Given the importance of flooding in both microhabitats, the lack of adaptive (between-microhabitat) genetic differentiation in these physiological traits probably reflects strong selection in the past against genotypes with phenotypic values below the range of phenotypes currently found (Ackerly et al. 2000). In contrast to expectation, genotypes from the lakeside microhabitat had an even lower aerenchyma content in their roots than genotypes from the landside microhabitat. This difference may be a consequence of adaptation to other environmental factors that vary along the flooding gradient. For example, the substrate at Lake Constance is coarser at the lakeside than at the landside microhabitat (Prati \& Peintinger 2000) and plants may therefore run a higher risk of desiccation during periods when water is at a low level. Because aerenchyma may enhance transpiration (Keeley 1979), selection in the lakeside microhabitat could have operated against an aerenchyma content that is any higher than is strictly required for toleration of flooding. An alternative explanation for the considerably lower aerenchyma content of lakeside geneotypes could be genetic correlations with other traits under selection as a consequence of pleiotropy or linkage (Stearns 1992).

Although genetic variation for both root aerenchyma (Fig. 3) and root starch content (Fig. 4) in R. reptans indicates a potential for evolution of these traits, we did not find evidence for selection on these traits under nonflooded or flooded conditions. Neither did the more flooding tolerant lakeside genotypes have a higher aerenchyma or carbohydrate content than the less flooding tolerant landside genotypes. Because the measured physiological traits cannot explain the difference in flooding tolerance between landside and lakeside genotypes, other traits must be responsible. We found selection for genotypes with short stolon internodes and small rosettes under long-flooded conditions (Fig. 5). Moreover, the more flooding-tolerant lakeside genotypes had significantly shorter stolon internodes than landside genotypes when grown under flooded conditions (Fig. 2f). This suggests that a higher flooding tolerance of lakeside genotypes is mainly a consequence of reduced sizes of modular units, which may result in lower respiratory losses (Setter \& Laureles 1996; Robe \& Griffith 1998).

\section{RESPONSE TO ENVIRONMENTAL CHANGES} INEVITABLY CONNECTED TO FLOODING

Although short stolon internodes increase fitness under flooded conditions, all genotypes increased the length of their stolon internodes in response to flooding, albeit to a lesser extent in lakeside than landside genotypes. Therefore, this plastic response to flooding appears maladaptive and is thus not likely to have been induced by flooding per se. Rather, the plastic increase in stolon length under flooded conditions was probably induced by reduced light intensity under water, as shown in previous work on $R$. reptans where plastic stolon internode elongation was found to be an adaptive response to shading (van Kleunen \& Fischer 2001). In that study, shading was imposed by competing grasses that naturally co-occur in the landside microhabitat but not in the lakeside microhabitat, where they cannot survive the long period of annual flooding.

Several authors have suggested that a trade-off between competitive ability and flooding tolerance constrains each species to a restricted range within flooding gradients (Keddy 1984; Grace 1990; Crawford 1992), but a mechanism for such a trade-off has rarely been suggested. Combined with earlier work on responses to competition (Prati \& Schmid 2000; van Kleunen et al. 2000; van Kleunen \& Fischer 2001), our results suggest that, at least for the creeping Ranunculus reptans, this trade-off may be due to stolon internode elongation: a 
smaller capacity for stolon internode elongation in response to shading of lakeside genotypes makes them better adapted to flooding but less well adapted for competition with grasses.

\section{Acknowledgements}

We thank Hannie de Caluwe, Annemiek Tiekstra, Laura Vincken, Gerard Bögemann and Harry van de Steeg for practical assistance and Heidrun Huber, Susan Kalisz and Eric Visser for valuable comments on earlier versions of the manuscript.

\section{References}

Ackerly, D.D., Dudley, S.A., Sultan, S.E., Schmitt, J., Coleman, J.S., Randall Linder, C. et al. (2000) The evolution of plant ecophysiological traits: recent advances and future directions. Bioscience, 50, 979-995.

Chan, J.W.Y. \& Burton, R.S. (1992) Variation in alcohol dehydrogenase activity and flood tolerance in white clover, Trifolium repens. Evolution, 46, 721-734.

Crawford, R.M.M. (1992) Oxygen availability as an ecological limit to plant distribution. Advances in Ecological Research, 23, 93-185.

Fischer, M., Husi, R., Prati, D., van Kleunen, M. \& Schmid, B. (2000a) RAPD variation among and within small and large populations of the rare clonal plant Ranunculus reptans (Ranunculaceae). American Journal of Botany, 87, 1128 1137.

Fischer, M., van Kleunen, M. \& Schmid, B. (2000b) Genetic Allee effects on performance, plasticity and developmental stability in a clonal plant. Ecology Letters, 3, 530-539.

Grace, J.B. (1990) On the relationship between plant traits and competitive ability. Perspectives on Plant Competition (eds J.B. Grace \& D. Tilman), pp. 51-63. Academic Press, San Diego, California.

He, J.B., Bögemann, G.M., Van de Steeg, H.M., Rijnders, J.H.G.M., Voesenek, L.A.C.J. \& Blom, C.W.P.M (1999) Survival tactics of Ranunculus species in river floodplains. Oecologia, 118, 1-8.

Hess, H.E., Landolt, E. \& Hirzel, R. (1980) Flora der Schweiz, Vol. 2. Birkhäuser, Basel, Switzerland.

Jensen, C.R., Luxmoore, R.J., Van Grundy, S.D. \& Stolzy, L.H. (1969) Root air space measurements by a pycnometer method. Agronomy Journal, 61, 474-475.

Justin, S.H.F.W. \& Armstrong, W. (1987) The anatomical characteristics of roots and plant response to soil flooding. New Phytologist, 106, 465-495.

Keddy, P.A. (1984) Plant zonation on lakeshores in Nova Scotia: a test of the resource specialization hypothesis. Journal of Ecology, 72, 797-807.

Keeley, J.E. (1979) Population differentation along a flood frequency gradient: physiological adaptations to flooding in Nyssa sylvatica. Ecological Monographs, 89, 89-108,

van Kleunen, M. \& Fischer, M. (2001) Adaptive evolution of plastic foraging responses in a clonal plant. Ecology, 82, 3309-3319.

van Kleunen, M., Fischer, M. \& Schmid, B. (2000) Costs of plasticity in foraging characteristics of the clonal plant Ranunculus reptans. Evolution, 54, 1947-1955.

Laan, P.M.J. \& Blom, C.W.P.M. (1990) Growth and survival responses of Rumex species to flooding and submerged conditions: the importance of shoot elongation, underwater photosynthesis and reserve carbohydrates. Journal of Experimental Botany, 41, 775-783.

Lande, K. \& Arnold, S.J. (1983) The measurement of selection on correlated characters. Evolution, 37, 1210-1226.
Lang, G. (1967) Die Ufervegetation des westlichen Bodensees. Archiv für Hydrobiologie, S23, 437-574.

Linhart, Y.B. (1988) Intrapopulation differentiation in annual plants. III. The contrasting effects of intra-and interspecific competition. Evolution, 42, 1047-1062.

Linhart, Y.B. \& Baker, I. (1973) Intra-population differentiation of physiological response to flooding in a population of Veronica peregrina L. Nature, 242, 275-276.

Linhart, Y.B. \& Grant, M.C. (1996) Evolutionary significance of local genetic differentiation in plants. Annual Review of Ecology and Systematics, 27, 237-277.

Lynn, D.E. \& Waldren, S. (2002) Physiological variation in populations of Ranunculus repens $\mathrm{L}$. (creeping buttercup) from the temporary limestone lakes (turloughs) in the west of Ireland. Annals of Botany, 89, 707-714.

Lynn, D.E. \& Waldren, S. (2003) Survival of Ranunculus repens $\mathrm{L}$. (creeping buttercup) in an amphibious habitat. Annals of Botany, 91, 75-84.

Norusis, M.J. (1999) SPSS for Windows. Release 10.0. SPSS Chicago, Illinois.

Payne, R.W., Lane, P.G.N.D., Harding, S.A., Leech, P.K. Morgan, G.W., Todd, A.D. et al. (1993) Genstat 5, Release 3, Reference Manual. Clarendon Press, Oxford.

Pollock, M.M., Naiman, R.J. \& Hanley, T. (1998) Plant species richness in riparian wetlands: a test of the biodiversity theory. Ecology, 79, 94-105.

Prati, D. \& Peintinger, M. (2000) Biological flora of central Europe: Ranunculus reptans L. Flora, 195, 135-145.

Prati, D. \& Schmid, B. (2000) Genetic differentiation of life-history traits within populations of the clonal plant Ranunculus reptans. Oikos, 90, 442-456.

Rausher, D. (1992) The measurement of selection on quantitative traits: biases due to environmental covariances between traits and fitness. Evolution, 46, 616-626.

Rijnders, J.H.G.M., Armstrong, W., Darwent, M.J., Blom, C.W.P.M. \& Voesenek, L.A.C.J. (2000) The role of flooding induced petiole elongation in Rumex palustris: measuring endogenous oxygen levels in petioles with micro-electrodes. New Phytologist, 147, 497-504.

Robe, W.E. \& Griffiths, H. (1998) Adaptations for an amphibious life: changes in leaf morphology, growth rate, carbon and nitrogen investment, and reproduction during adjustment to emersion by the freshwater macrophyte Litorella uniflora. New Phytologist, 140, 9-23.

Sand-Jensen, K. \& Frost-Christensen, H. (1999) Plant growth and photosynthesis in the transition zone between land and stream. Aquatic Botany, 63, 23-35.

Setter, T.L., Ellis, M., Laureles, E.V., Ella, E.S., Senadhira, D., Mishra, S.B. et al. (1997) Physiology and genetics of submergence tolerance in rice. Annals of Botany, 79, 67-77.

Setter, T.L. \& Laureles, E.V. (1996) The beneficial effect of reduced elongation growth on submergence tolerance of rice. Journal of Experimental Botany, 47, 1551-1559.

Silvertown, J.W., Dodd, M.E. \& Gowing, D.J.G. (2001) Phylogeny and the niche structure of meadow plant communities. Journal of Ecology, 89, 428-435.

Silvertown, J.W., Dodd, M.E., Gowing, D.J.G. \& Mountford, J.O. (1999) Hydrologically defined niches reveal a basis for species richness in plant communities. Nature, 400, 61-63.

Sokal, R.R. \& Rohlf, F.J. (1995) Biometry, the Principles and Practice of Statistics in Biology Research. Freeman, San Francisco.

Stanton, M.L., Galen, C. \& Shore, J. (1997) Population structure along a steep environmental gradient: consequences of flowering time and habitat variation in the snow buttercup, Ranunculus adoneus. Evolution, 51, 79-94.

Stearns, S.C. (1992) The Evolution of Life Histories. Oxford University Press, Oxford

Sultan, S.E. \& Bazzaz, F.A. (1993) Phenotypic plasticity in Polygonum persicaria. II. Norms of reaction to soil moisture and the maintenance of genetic diversity. Evolution, 47, $1032-1049$. 
Vartapetian, B.B. \& Jackson, M.B. (1997) Plant adaptations to anaerobic stress. Annals of Botany, 79 (Suppl. A), 3-20.

Vervuren, P.J.A., Blom, C.W.P.M. \& de Kroon, H. (2003) Extreme flooding events on the Rhine and the survival and distribution of riparian plant species. Journal of Ecology, 91, 135-146.

Visser, E.J.W. \& Bögemann, G.M. (2003) Measurement of porosity in very small samples of plant tissue. Plant and Soil, 253, 81-90.

Voesenek, L.A.C.J., Rijnders, J.H.G.M., Peeters, A.J.M., van de Steeg, H.M. \& de Kroon, H. (2004) Plant hormones regulate fast shoot elongation under water: from genes to community. Ecology, 85, 16-27.

Yemm, E.W. \& Willis, A.J. (1954) The estimation of carbohydrates in plant extracts by anthrone. Biochemistry Journal, $57,508-514$. 